\title{
Ectopia Cordis in a Nellore Jodipi Lamb - A Case Report
}

\author{
B.C. Parthasarathi ${ }^{1}$, Kaushlendra Singh ${ }^{1}$, Aquil Mohmad ${ }^{1}$, Nisha Bisht ${ }^{1}$, \\ Shobha Yadav', Suresh kumar ${ }^{2 *}$ and Ajay Munigadapa ${ }^{3}$ \\ ${ }^{1}$ ICAR-IVRI-Bareilly, India \\ ${ }^{2}$ ICAR-NDRI-Karnal, India \\ ${ }^{3}$ Laxmanchanda, Adilabaddistrict, Telangana, India \\ *Corresponding author
}

\section{A B S T R A C T}

\section{Keywords}

Ectopia Cordis,

Nellore Jodipi

Lamb

Article Info

Accepted:

15 March 2019

Available Online:

10 April 2019
This case study was aimed to report the Ectopia cordis in a lamb. A Nellore Jodipi male lamb was presented at the Veterinary Hospital. Clinical examination revealed tachypnea, tachycardia and the presence of an ectopic heart located in the pectoral region. Surgery was performed but the lamb died. Postmortem revealed an opening in the sternum with the presence of a fibrous pericardium attached by ligaments

\section{Introduction}

Ectopia Cordis is a congenital malformation wherein heart is abnormally located either partially or completely outside the thoracic cage, in the ventral cervical, in sternal (pectoral) or in abdominal regions (Bowen and Adrian, 1962; Herzog and Wiedeking, 1970) with the highest incidence (82\%) in cervical region (Hiraga and Abe, 1986). Failure of proper maturation of mid line mesoderm and alteration in tissue differentiation in embryonic disc leads to development of Ectopia Cordis (Roberts, 1971). Congenital cardiac anomalies occur in all species including the human (Reppas et al., 1996; Dadich, 2000; Upadhye and Dhoot, 2001; Kabbani et al., 2002; Hamali and Ashrafihelan, 2010). Some cases with cardiac abnormality may survive to maturity, while others may develop heart failure when subjected to physical stress. The present report describes a case of Ectopia Cordis in a Nellore Jodipi Lamb.

A Nellore Jodipi male Lamb was presented to Veterinary hospital, Laxmanchanda village, Nirmal, Adilabad district, Telangana. The lamb showed bulging around postxiphoidregion (Fig.1) with signs of an early exertion. Physical examination revealed normal pulse (94/min) and, respiration (272 
/min) rates and rectal temperature (100.4\% F). Feeding, drinking water, urination and defecation were normal. Palpation at the bulged area revealed throbbing. Auscultation showed heart beat in this area. The size of the bulge was increasing on bleating. Physical examination of the bulge further revealed a hernial ring formed anteriorly by bones and posteriorly by abdominal muscle through which the apex of the heart was herniated. The Lamb survived for six months. On postmortem examination, incomplete closure of ventral abdominal wall was evident through which apex of the heart was protruding Congenital defects are present at birth. They may affect a single anatomical structure or function, an entire system, parts of several systems or both a structure and a function (Morrow, 1986).
In the present case it was congenital abnormality of musculoskeletal system leading to protrusion of the heart through incompletely closed ventral wall. Palpation and auscultation in the bulged area aroused suspicion of ectopic heart through the palpable ring. The apex of heart was directed caudo-medially towards the liver and separated by diaphragm. Post-mortem examination further confirmed clinical and sonographic observations. In general, prognosis for Ectopia cordis is poor, most cases results in death shortly after birth due to infection, hypoxemia or cardiac failure (Bernstein, 2011) or animal may live longer as well (Bowen and Adrian, 1962; Windberger et al., 1992; Ken et al., 2011).

Fig.1 Lamb showing bulging around post-xiphoid region (arrow)

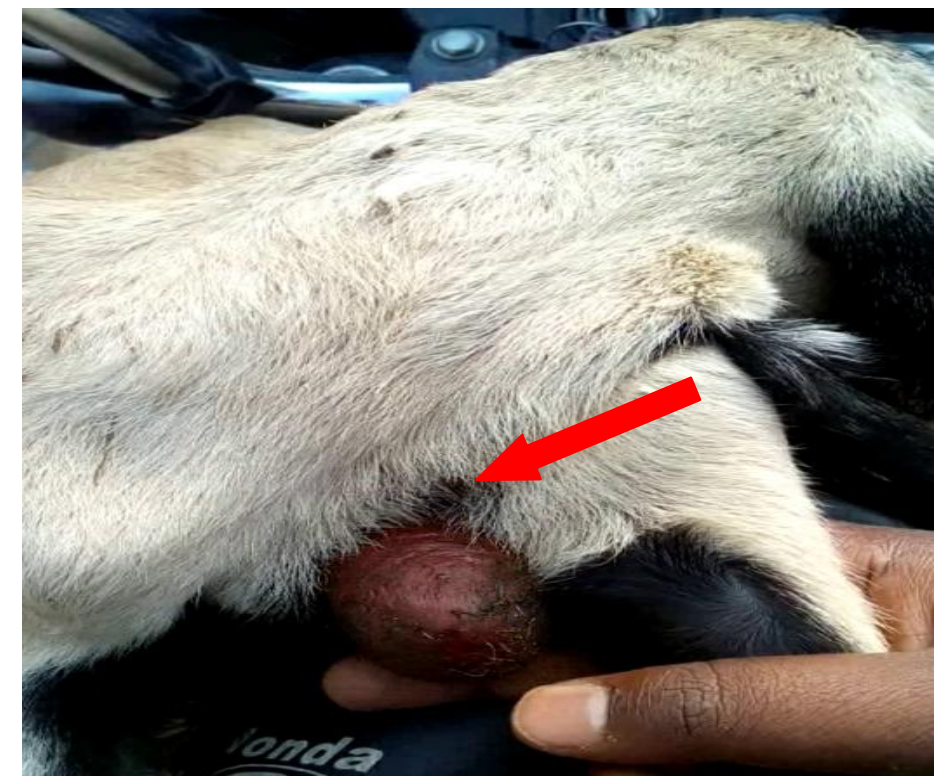

A male Nellore Jodipi lamb was presented with signs of early exertion and bulging at post- xiphoid region diagnosed as Ectopia Cordis through palpation, auscultation. Ectopia Cordis is a congenital malformation and due to which duration of animal life may vary from a day to years.

\section{Acknowledgement}

The authors are very thankful to Dr.Ajay Munigadapa (Veterinary Assistant Surgeon), Laxmanchanda, Adilabad district, Telangana for providing necessary help and permission for publication. 


\section{References}

Bernstein, D. 2011. Kliegman: Nelson Text Book of Pediatrics. Elsevier Publishers, p. 1599.

Bowen, J.M. and Adrian, R.W. 1962. Ectopia Cordis in cattle. Journal of American Veterinary Medical Association 141: 1162-1167.

Dadich, G.N. 2000. Ectopia Cordis in goat. Indian Veterinary Journal 77: 898.

Hamali, H. and Ashrafihelan, J. 2010. A report on bovine fetal Ectopia Cordis cervicalis associated with two cervical sacs. Iranian Journal of Veterinary Research 11: 287-290.

Herzog, A. and Wiedeking, J.F. 1970. Ectopia cordis congenital beim rind. Giessener Beiträge zur Erbpathologie und Zuchthygiene 1-2: 1-24.

Hiraga, T. and Abe, M. 1986. Eight calves of cervical Ectopia Cordis and their sternums. Japanese Journal of Veterinary Science 48: 1199-1206.

Kabbani, M.S., Rasheed, K., Mallick, M.S., Abu-Hassan, H. and Al-Yousef, S. 2002. Thoraco abdominal Ectopia Cordis: case report. Annals Saudi Medicine 22: 5-6.
Ken, O., Masanori, S., Keeko, N., Reiichiro, S., Sachiko, A., Kazuyuki, K., Seigo, I., Makoto, M., Tsunenori, S., Yoshito, W. and Yasunori, W. 2011. Long term survival of a cow with cervical Ectopia Cordis. Canadian Veterinary Journal 52: 667-669.

Morrow, D.A. 1986. Current Therapy in Theriogenology. 2 edn., Philadelphia, W.B. Saunders Co., pp 177-199.

Reppas, G.P., Canfield, P.J., Hoffman, K.L., Hartley, W.J. and Hutchins, D.R. 1996. Multiple congenital cardiac anomalies and idiopathic thoracic aortitis in horses. Veterinary Record 138: 14-16.

Roberts, S.J. 1971. Veterinary Obstetrics and Genital nd Diseases. 2 edn., CBS Publishers and Distributors, pp: 62-63. Upadhye, S.V. and Dhoot, V. M. 2001. A case of Ectopia cordis in a goat. Indian Veterinary Journal 78: 1028-1029.

Windberger. U., Forstenpointner, G. and Grabenwoger, F. 1992. Cardiac function, morphology and chromosomal aberrations in a calf with Ectopia cordiscervicalis. Zentralblatt fur Veterinarmedizin 39: 759-768.

\section{How to cite this article:}

Parthasarathi, B.C., Kaushlendra Singh, Aquil Mohmad, Nisha Bisht, Shobha Yadav, Suresh kumar and Ajay Munigadapa. 2019. Ectopia Cordis in a Nellore Jodipi Lamb - A Case Report. Int.J.Curr.Microbiol.App.Sci. 8(04): 1829-1831. doi: https://doi.org/10.20546/ijcmas.2019.804.212 